\title{
Community-based Intervention to Strengthen Family and Community Relationships in Post-conflict Nwoya and Gulu Districts in Northern Uganda
}

\author{
Joanne N. Corbin and Julius Omona
}

Armed conflict and displacement disrupt the social, economic, and cultural networks necessary for individuals' and families' well-being. Interventions are necessary to repair this damage, as there are an estimated 40 million people displaced worldwide due to conflict and violence. This article describes the Dialogue Groups, a community-based intervention in post-conflict northern Uganda, focusing on social disruptions such as men's decreased involvement in the family, women's increased responsibilities at home and in the family, and increased violent behavior in homes. Reported outcomes include increased connection among community members and within homes, decreased genderbased violence, and increased livelihood opportunities. The intervention utilized an empowerment approach and demonstrated that community-driven and community-led interventions addressing social disruptions of conflict and displacement are viable and can meet the goals of a social development agenda.

Keywords: community-based intervention, empowerment approach, internal displacement, northern Uganda, post-conflict, social disruption

Joanne N. Corbin, PhD, LCSW, is a professor and director of the Smith College School for Social Work, PhD Program. Dr. Corbin's research and practice focuses on the effect of armed conflict on former child soldiers and displaced populations. She has no conflict of interest in this current article. She can be contacted at joanne.corbin@uconn.edu. Julius Omona, born in 1962 in Uganda, is currently an Associate Professor in Department of Social Work and Social Administration, Makerere University. His areas of academic specialties are Education, Civil Society, Community Development, Post-conflict, and Disability where he has widely published and presented conference papers both locally and internationally. He is also the founder of Anaka Foundation, located in the Nwoya district of Northern Uganda, and empowers the vulnerable communities, mainly women, children, and the youth, and builds their capacity through training, sensitization, and material gifts. He has no conflict of interest in this current article. He can be contacted at omonaju@chuss.mak.ac.ug 


\section{Introduction}

Armed conflict and internal displacement disrupt the social, cultural, and economic networks that ensure families' and communities' well-being (Unruh, 2008). Such disruptions are not resolved even at the end of the conflict, and individuals must rebuild their lives with limited support from governmental resources (Corbin, 2019). Attention to interventions that address the social development needs of families and communities in post-conflict settings is needed, as there are an estimated 40 million individuals displaced as a result of conflict and violence (IDMC, 2018).

This article describes a community-based intervention that addresses the social, economic, and cultural disruptions in post-conflict northern Uganda. The intervention, Dialogue Groups to Strengthen Family and Community Relationships (hereinafter referred to as Dialogue Groups), was based on findings from a qualitative study conducted by the first author that identified a need for strengthening relationships within families and communities to achieve community sustainability and improved livelihoods, consonant with a social development approach. This article describes this intervention, the collaborative process among stakeholders, and the initial responses from the community. This intervention is located within empowerment theory (Lee, 1996; Mancoske \& Hunzeker, 1990) and recent literature on interventions addressing community well-being during a post-conflict scenario. Frameworks of social development and the postconflict agenda locate this intervention within the needs of a post-conflict setting. Recommendations for interventions enhancing community well-being in similar post-conflict settings are offered.

\section{Context of Dialogue Groups}

The intervention was launched in 2016 in the Gulu and Nwoya districts in northern Uganda. The populations of Gulu and Nwoya districts are 275,613 and 133,506, respectively, based on Uganda's 2014 census (UBOS, 2020). The major ethnic group in both districts is the Acholi, and the language spoken by most people is Acholi (Luo). The cultural orientation of the population is predominantly collectivistic. Agriculture is the basis of family livelihoods in these districts, with most families producing food for domestic use and for income (UBOS, 2018).

Northern Uganda suffered a prolonged insurgency from 1986 to 2006, waged by different rebel groups within different and sometimes overlapping time scales. These included the Uganda People's Democratic Army (UPDA) between 1986 and 1988; the Holy Spirit Movement between 1986 and 1987; and the longest and the most brutal one-the Lord's Resistance Army (LRA), between 1988 and 2006 (Omona \& Aduo, 2013). Approximately, 1.8 million individuals in northern Uganda were relocated to internally displaced persons (IDP) camps (IDMC, 2011). IDP camps were environments of gross deprivation, and humanitarian relief and military control were features of daily life (Branch, 2011; Finnström, 2008; Madden \& Ross, 2009). The armed conflict was effectively reduced with the 
signing of a cessation of hostilities agreement between the LRA and the Ugandan government in 2006. Although the final peace agreement scheduled for 2008 with the LRA was never signed, the majority of displaced individuals began resettlement in 2006 (IDMC, 2010).

The post-war period in northern Uganda continues to the present day. The region has been undergoing a period of recovery and reconstruction with the intervention of local and global civil society actors and government-led initiatives, all framed within the First and Second National Development Plans (NDP I 2010/11-2014/2015; NDP II, 2015/16-2019/2020) (GoU, 2015).

Poverty is a major issue in both districts in northern Uganda, with poverty estimates of $32.5 \%$ for the northern region (UBOS, 2018). Both districts have unfavorable development indicators (literacy, primary education enrollment, dietary energy consumption), compared to the major regions of the country, due largely to the effects of the armed conflict (UBOS, 2018).

\section{Effect of Armed Conflict and Displacement on Families and Communities}

Ntakiyimana (2005) summarized the effects of armed conflicts on families in the following aspects: (1) conflicts among families and allies; (2) family separation; (3) destruction of home livelihoods; and (4) violence, fraud, and spoliation. These disruptions weaken community values, norms, and social capital. Social, cultural, and economic networks critical to sustaining livelihoods, land ownership, household income, safety and order of communities, and educational systems are broken as a result of displacement (Unruh, 2008). Displaced individuals were moved from their areas of origin to the IDP camps, where people no longer had access to farmlands or other means of livelihood. Renting land near the camp for farming was very expensive and placed women at risk of abduction and rape due to the solitary nature of the work. Social norms and practices were affected, as individuals' behaviors, such as excessive drinking, stealing, and inappropriate sexual behaviors, were shaped by the conditions of the camps (Roberts et al., 2009).

Women and children were most affected due to the disruption of food supplies, destruction of crops and agricultural infrastructure, disintegration of families and communities, displacement of populations, and destruction of educational and health services and of water and sanitation systems (Machel, UNICEF, \& UN, 1996). Effects of displacement and armed conflict on women include women's loss of social and cultural identity (Meertens \& Stoller, 2001), women's loss of familial connection necessary to attain access to land (Whyte, Babiiha, Mukyala, \& Meinert, 2013), women's economic hardship due to the loss of social networks (Makhoul \& Ghanem, 2009), and women's vulnerability to gender-based violence (GBV) (Blay-Tofey \& Lee, 2015; Kohli et al., 2015).

\section{Frameworks for Conceptualizing the Dialogue Groups}

Social development and the post-conflict agenda contribute important understandings to the development of socio-cultural interventions in post-conflict 
settings. Social development is conceptualized as a "value-based, multilevel, and multidimensional approach to the development of a society, with the ultimate goal being to enhance the well-being of the people of that society" (Cox \& Pawar, 2013, p. 4, para 2). A social development approach empowers individuals to make decisions about their lives by increasing access to the basic goods and services needed to sustain life, including raising standards of living for all groups within the context, especially those at risk and marginalized; and expanding individuals' range of economic and social choices (Hochfeld, 2010). The Dialogue Groups is a community-based initiative that strengthens individuals' ability to raise the standard of living for those in a post-conflict community.

To further situate this intervention, Cox and Pawar (2013) developed a framework for conceptualizing the tasks to be addressed during post-conflict at the local, district, national, and international levels. Group A tasks include the largescale responses, such as a peace agreement, resettlement of displaced individuals, and reduction in conflict between groups. Group B tasks involve a comprehensive approach for the populations' well-being, such as attention to resources of food, shelter, and health. Group C tasks are those related to the underlying causes of the conflict, such as the political and economic disparities that create social injustice. The Dialogue Groups focused on Group B tasks, addressing the well-being of families and communities, specifically emotional health, family and community stability, and income generation.

Utilizing a social development approach and the post-conflict agenda enabled the intervention developers to address the well-being of individuals in the community within the needs of a post-conflict context.

\section{Recent Interventions}

Family-focused interventions in post-conflict settings have demonstrated significant improvement in family interactions. A 10-session educational program to decrease harsh and punitive parenting and improve caregiver-child interactions in post-war Liberia demonstrated decreased use of harsh discipline, increased positive behavior management strategies, and increased positive interactions between caregivers and children (Puffer et al., 2015). An intervention in Rwanda to address conflict in families affected by the human immunodeficiency virus evidenced significant reduction in alcohol use and intimate partner violence (IPV) (Chaudhury et al., 2016). In this intervention that involved 10 home visits, families developed a family narrative to address resilience, improve family communication, and provide education on parenting skills.

Community-based interventions have produced positive social and economic outcomes in post-conflict settings. In Nicaragua, a community-based intervention increased social capital through strengthening the management and leadership skills of community members (Brune \& Bossert, 2009). This increase in social capital - increased participation, increased attendance, and increased trust and feelings of closeness with others in the community—was associated with better 
health practice outcomes. Another participatory community-based approach in five conflict-affected countries resulted in increased awareness of women's rights and their increased ability to speak out against GBV, improved communication within the home, and reduced violence (Gurman et al., 2014).

Lastly, a group intervention addressing depression and posttraumatic stress symptoms of individuals in post-conflict northern Uganda evidenced decreases in depression and posttraumatic stress symptoms (Nakimuli-Mpungu et al., 2013). While this intervention is not family-based or community-based, it is included here for its relevance to the viability of groups in creating positive changes in mental health symptoms in post-conflict settings. Group members shared trauma experiences, learned relaxation techniques and positive coping strategies, and received psychoeducation on common mental health issues to support individuals and the community on mental health treatment compliance.

Features of these interventions that are relevant to the Dialogue Groups include the use of lay facilitators in a low-resource context (Puffer et al., 2015), and the use of psychoeductional sessions to achieve objectives (Chaudhury et al., 2016; Nakimuli-Mpungu et al., 2013; Puffer et al., 2015). Centering the interventions on participant experiences is important for intervention effectiveness (Chaudhury et al., 2016; Gurman et al., 2014; Nakimuli-Mpungu et al., 2013).

Implementation challenges of these family-focused and community-based interventions in post-conflict settings include the shortage of professionals with mental health training, the use of nonspecialists in providing the interventions, attrition of lay workers, danger and instability of post-conflict settings, the lack of facilities and transportation, and insufficient funding (Murray et al., 2014). In addition, men's culturally based negative attitudes of women's inferiority compounded with high rates of illiteracy of women contributed to women not being aware of their rights and ability to advocate for services to improve their welfare (Omona \& Aduo, 2013). These researchers also found gender insensitivity in the post-conflict program designs that failed to incorporate women's perspectives on issues. This brief review of recent literature of family-focused and community-based interventions in post-conflict settings demonstrates the efficacy of such interventions in low-resource contexts and identifies common challenges.

\section{Empowerment Theory}

The intervention of Dialogue Groups is premised on the empowerment approach (Lee, 1996; Mancoske \& Hunzeker, 1990). Empowerment is defined as, “...using interventions which enable those with whom we interact to be more in control of their interactions in our exchanges and broadening to other dimensions of their interactions" (Mancoske \& Hunzeker, 1990, p. 14). This conceptualization of empowerment aligns with the goal of social development, which is to enhance the well-being of people in a society (Cox \& Pawar, 2013), and provides understanding of how enhancement of people's well-being must occur-by enabling individuals with whom practitioners work to be more in control of their circumstances. 
Empowerment theory postulates two necessary preconditions: a practitioner with raised consciousness and an individual receiving the intervention who seeks to be empowered (Lee, 1996). The theory further states that the role of the practitioner is to promote reflection, thinking, and problem-solving on person-environment transactions. There is focused attention on power imbalances and resource availability at all levels and among all levels of the ecological system, specifically the individual, micro-, meso-, exo-, and macro-systems of the social ecology (Germain \& Gitterman, 1996; Lee, 1996). Strong family and community support networks mitigate the effects of structural oppression on an individual (Lee, 1996). This is precisely what the Dialogue Groups sought to achieve-enhanced functioning within communities and households through improved relationships between men and women.

\section{Guiding Principles of Dialogue Groups}

Deepening the application of the empowerment approach, the intervention developers identified five guiding principles for this intervention. First, this intervention was participant driven and participant led. The intervention grew from participant's interest and energy; it was not imposed upon the community. Second, this intervention was based on research that privileged women's subjective experiences of how conflict and displacement affected them, their families, and their communities. Third, the intervention was heterogeneous, purposely including men. Programs designed to strengthen women's development must intentionally include men to counter the social and economic ruptures in these relationships related to conflict and displacement. Fourth, each module attended to the intersecting nature of the social, cultural, and economic domains in women's lives. Fifth, sustainability was considered from the outset as many programs cease when the accompanying funding ends. This intervention was supported largely through volunteer efforts.

\section{Development of the Dialogue Groups' Intervention}

Findings from a qualitative study exploring women's subjective experiences of the socioeconomic changes resulting from armed conflict and internal displacement in northern Uganda guided the development of this intervention (Corbin, 2019). Findings specific to this intervention included: (1) women's increased responsibility for cultivating food and providing income for their households due to men's decreased involvement in family responsibilities; (2) women's increased land vulnerability due to changes in marriage practices that affected women's access to land and land conflicts; (3) men's increased consumption of alcohol; and (4) men's increased engagement in domestic violence toward women.

All findings were shared with the communities in which the study was conducted, allowing women and men to discuss the findings together. Community members concurred with the reported findings and voiced interest in addressing 
these concerns. These discussions resulted in the development of a year-long project of monthly facilitated discussions - the Dialogue Groups. Primary objectives of the intervention were: (1) improvement of relationships between men and women, among women, and among all members of community; (2) increasing male involvement within families; and (3) strengthening families through improving the health and well-being of group participants and their household members through provision of information. A secondary objective was to increase family income by providing group members with information on strengthening economic strategies.

Nine individuals were primarily responsible for the development of the intervention - these included two university faculties, one religious leader, the director of a non-government organization, social workers, and several community leaders. Community members advised on most aspects of the intervention. Monthly Dialogue Group discussions were recommended versus more frequent discussions due to community members' need to attend to cultivation responsibilities. The length of the discussions was agreed to be 90-120 minutes. Topics for the monthly discussion groups were derived from the research findings, with several additional suggestions from community members. These topics were respect, communication skills, clear boundaries (gender norms), relationships and marriage, livelihood strategies, cooperation, GBV/domestic violence, hygiene and health, women are not "mere women" (addressing community examples of gender bias), treatment of children and step-children, and women's access to land (Corbin, 2016). The twelfth and the final module provided reflection on all modules and group closure.

Group facilitators were selected by the authors based on their involvement with the initial study and their relationship with the community. Authors provided initial training to the facilitators and ongoing consultation. Five groups formed the initial research communities, with a recommended group size of 20 men and women in order to support group cohesion. Authors developed a manual containing the modules with instructions for group facilitators. Each module followed a three-segment format of large group discussion, smaller break-out group discussion and problem-solving, and larger group sharing. Each segment had guided questions to address discussion points, help in problem-solving, and determine the next steps.

\section{Discussion of Narrative Findings of Dialogue Groups}

At the end of the first year, all groups were meeting monthly and had an attendance of 15 to 20 men and women. Group members demonstrated the ability to work together through challenges and formed supportive relationships outside of the groups. Four groups developed an income-generating and savings project, such as raising chickens and growing crops, like rice or grains, to complement the monthly discussions. The income-generating projects addressed the pressing needs of the group members to pay children's school fees or meet medical 
expenses. The fifth group decided on a community project of building a church. Group members contributed to the digging of the foundation, making of bricks, and constructing of the walls. These examples demonstrate members' active engagement in projects that contributed to their well-being, thereby attaining a premise of the empowerment approach (Mancoske \& Hunzeker, 1990). Groups established relationships with individuals knowledgeable in income generation, health and medicine, and laws on land rights and GBV who shared their expertise with the groups. Developing such relationships has a direct bearing on the individuals' well-being, helps to raise standards of living for all within these communities, and strengthens members' social capital, thereby supporting principles of social development (Hochfeld, 2010).

Group members spoke of the usefulness of specific discussion topics in their day-to-day lives. Thus, this intervention satisfies a second premise of the empowerment approach, that by promoting reflection, thinking, and problem-solving on person-in-environment transactions, the facilitated discussions encouraged participants to think about themselves in connection with others in the group, in the larger community, and in the district as a whole. For example, Respect was a topic that resonated with all the groups and contributed to the improved relationships with their spouses and within their homes. Another example is that the topic of Clear Boundaries helped community members to consider flexibility rather than rigidity regarding gender roles and responsibilities.

The intervention gave utmost importance to the subjective experiences of women. The structure of the intervention and the facilitation enabled women to voice their experiences and engage in discussions with men. Members identified decreases in GBV and men's alcohol use as a result of their discussions. The intervention contributed to a third premise of the empowerment approach, raising the consciousness of those developing and facilitating these groups as well as the group participants (Mancoske \& Hunzeker, 1990). One group facilitator stated, "The Dialogue Groups was a real intervention helping to stabilize the community."

Table 1 provides selected quotes (through an interpreter) from group members aligned with objectives of the intervention.

The reported outcomes of better interaction between men and women, increased feelings of connection within the group, increased participation of males in family responsibilities, decreased GBV, and better information about economic opportunities are positive signs of the intervention. Group members have indicated a desire to continue beyond the initial 12 sessions and to scale-up the number of groups in the communities.

\section{Challenges and Limitations}

One challenge noted by group members was the continuing health concerns of the community, including Hepatitis B, dental problems, and the poor health of elders and children. As one participant described, these health issues were "making 
Table 1 Dialogue Group primary objectives and participant quotes (via interpreter)

\begin{tabular}{|c|c|}
\hline Intervention objectives & Quotes from participants \\
\hline $\begin{array}{l}\text { Improve relationships between } \\
\text { men and women, among } \\
\text { women, and among all members } \\
\text { of community }\end{array}$ & $\begin{array}{l}\text { "Members in the [name] group discussed how everyone } \\
\text { in this group is like a family." } \\
\text { "Being in the group ... he feels connected. Has trust } \\
\text { among the group. He can share in other people's } \\
\text { problems." } \\
\text { "The discussion on Cooperation has reminded her that } \\
\text { this has broken down in the community." }\end{array}$ \\
\hline $\begin{array}{l}\text { Increase male involvement within } \\
\text { families }\end{array}$ & $\begin{array}{l}\text { "The group has helped them let go of parts of culture } \\
\text { that are not very helpful." } \\
\text { "The training is helping men to plan together with the } \\
\text { wife how to spend the money that is earned and not just } \\
\text { decide alone." }\end{array}$ \\
\hline $\begin{array}{l}\text { Strengthen families through } \\
\text { improving the health and } \\
\text { well-being of group participants } \\
\text { and their household members } \\
\text { through provision of information }\end{array}$ & $\begin{array}{l}\text { "She was frustrated because she was bitter and lonely. } \\
\text { Through the training she has been motivated to do } \\
\text { things. Also, the boli cup (savings activities) has helped } \\
\text { her to save." } \\
\text { "Violence has decreased as well as drinking of alcohol." }\end{array}$ \\
\hline
\end{tabular}

the community poor." A second challenge was the request that group members be provided an incentive (money, seeds, or food) in return to their participation in the group. While some community members did not participate due to lack of incentive, those who continued did so because they gained knowledge and social support, which would help increase their future income. Lastly, earning money to care for families, send children to school, and buy medicine is still a challenge, and the group members requested for a stronger focus on income generation.

Group facilitators identified additional challenges, such as electricity outages, poor cell network, and lack of money for phone calls. These challenges hampered their ability to communicate with their members, each other, and the intervention developers.

\section{Conclusion}

All participants in the Dialogue Groups experienced the LRA conflict, and many were children or adolescents during that period. They have experienced deaths in the family and separations from family, violence of war, food insecurity, and interrupted education opportunities. Even those born after the war grew up in families and communities that were socioeconomically devastated by the conflict. In such a context, and within a patriarchal cultural system, most group members experience oppression, discrimination, hopelessness, and abject poverty. The Dialogue Groups, through which the entire community was given the opportunity to collectively share their experiences, participate in knowledge and skill-building activities to help group members break some of the barriers to empowerment within 
themselves, their households, and their communities, was a well-matched intervention for this community.

The Dialogue Groups' intervention has demonstrated modest effectiveness and strong relevance to the needs of these post-conflict communities. It is important to note that this project incorporated several aspects of the earlier discussed projects - use of lay facilitators, modules, and participants defining the content to be addressed. Although reliance on minimal resources aided sustainability, it also limited financial support for facilitators' efforts and expenses, and group members' interest in income generation. One next step is the identification of sources of financial support or partnership with indigenous civil society organizations to support the specific economic objectives of the groups. A second step is to implement the intervention in a wider number of districts in northern Uganda to demonstrate effectiveness and build stronger connections to district-level programs and policy development that can lead to a process of planned change, which is a necessary aspect of social development (Midgley, 2014). A third step is an empirical examination of these outcomes to build knowledge of community-based, community-driven, and community-led sustainable community interventions in resource-limited, post-conflict contexts.

It is important to note that this intervention is aligned with the broader planning frameworks of Peace, Recovery and Development Plan (2015/2020) for this region. The NDP I and II aforementioned and the Uganda Vision 2040, all of which variously emphasize the significance of community-based, participatory and bottom-up interventions by all stakeholders in order to alleviate poverty and deprivation (GoU, 2015). The Dialogue Groups is an intervention that can support the development of stronger community relationships that would allow community members to participate in the economic and political decision-making with a stronger voice and relationships.

While the next steps for this project are clear-identification of resources for empowerment and program development, wider implementation, and empirical examination - there are reflections that can be advanced to program developers in similar post-conflict contexts.

First, an intervention that is developed from the identified needs of a conflictaffected community rather than an intervention that is brought into a community is viable and can garner significant buy-in and leadership from individuals and families in those communities. Second, this intervention held communities' members responsible as the facilitators, and this created opportunities for community members to assume leadership responsibilities in their communities. This was a significant role for many women experiencing gender bias. Third, this intervention demonstrated that involving men in discussions with women can change men's understanding from the perspective of women, and men's and women's understanding of their relationships.

Interventions that incorporate these reflections support the highest aims of empowerment - to enhance the well-being of people in a community-while 
enabling those participating in the intervention to be at the center of developing the intervention, implementing the intervention, and benefitting from the intervention. Such interventions can affect family and community relationships and income-generation outcomes for those in post-conflict settings.

\section{Acknowledgments}

The contribution of the following, to the entire project, cannot be ignored: Father Remigo Obol, Awach Parish Gulu District; Mrs. Margaret Omona, Executive Director, Anaka Foundation; and Ms. Jackie Corbin, Armstrong Consultant. Others, who were group facilitators, were Ms. Florence Anyayo, Ms. Lucy Olanya, Ms. Grace P’Lajok Lanyero, and Ms. Concy Alanyo.

\section{References}

Blay-Tofey, M., \& Lee, B. X. (2015). Preventing gender-based violence engendered by conflict: The case of Côte d'Ivoired'Ivoire. Social Science E Medicine, 146, 341-347. doi:10.1016/j.socscimed.2015.10.009

Branch, A. (2011). Displacing human rights: War and intervention in northern Uganda. New York, NY: Oxford University Press.

Brune, N. E., \& Bossert, T. (2009). Building social capital in post-conflict communities: Evidence from Nicaragua. Social Science \& Medicine, 68, 885-893. doi:10.1016/j.socscimed.2008.12.024

Chaudhury, S., Brown, F. L., Kirk, C. M., Mukunzi, S., Nyirandagijimana, B., Mukandanga, J., ... Betancourt, T. S. (2016). Exploring the potential of a family-based prevention intervention to reduce alcohol use and violence within HIV-affected families in Rwanda. AIDS Care, 28, 118. doi:10.1080/09 540121.2016.1176686

Corbin, J. N. (2016). Dialogue group modules: Strengthening relationships between men and women in northern Uganda. Northampton, MA: Author.

Corbin, J. N. (2019). Effect of armed conflict and displacement on women's social, cultural and economic roles and responsibilities in northern Uganda. Journal of Refugee Studies. Advance published online March 25, 2019. doi:10.1093/ $\mathrm{jrs} / \mathrm{fez} 015$

Cox, D. R., \& Pawar, M. S. (2013). International social work: Issues, strategies, and programs. SAGE Publications. Retrieved from http://search.ebscohost.com/ login.aspx? direct=true $\& d b=$ cat00321a\&AN=fivecol.016523272\&site=edslive \&scope $=$ site

Finnström, S. (2008). Living with bad surroundings: War and history, and everyday moments in northern Uganda. Durham, NC: Duke University Press.

Germain, C. B., \& Gitterman, A. (1996). The life model of social work practice: Advanced theory and practice. New York, NY: Columbia University Press.

Government of Uganda (GoU). (2015). Second national development plan 2015/162019/20 (NDP II). Government of Uganda, National Planning Authority. 
Retrieved from http://www.npa.go.ug/development-plans/nationaldevelopment-plan-ndp/

Gurman, T. A., Trappler, R. M., Acosta, A., McCray, P. A., Cooper, C. M., \& Goodsmith, L. (2014). "By seeing with our own eyes, it can remain in our mind": Qualitative evaluation findings suggest the ability of participatory video to reduce gender-based violence in conflict-affected setting. Health Education Research, 29(4), 690-701. doi:10.1093/her/cyu018

Hochfeld, T. (2010). Social development and minimum standards in social work education in South Africa. Social Work Education, 29, 356-371. doi:10.1080/02615470903055463

Internal Displacement Monitoring Centre (IDMC). (2010). Internal displacement: Global overview of trends and developments in 2009. Geneva, Switzerland: IDMC. Retrieved from https://www.internal-displacement.org/publications/internaldisplacement-global-overview-of-trends-and-developments-in-2009

Internal Displacement and Monitoring Centre (IDMC). (2011). Unprepared for peace: Education in northern Uganda in displacement and beyond. Geneva, Switzerland: IDMC. Retrieved from http://www.internal-displacement.org/ publications/unprepared-for-peace-education-in-northern-uganda-indisplacement-and-beyond

Internal Displacement and Monitoring Centre (IDMC). (2018). Global report on internal displacement 2018. Retrieved from http://www.internal-displacement.org/global-report/grid2018/

Kohli, A., Perrin, N., Mpanano, R. M., Banywesize, L., Mirindi, A. B., Banywesize, J. H., ... Glass, N. (2015). Family and community driven response to intimate partner violence in post-conflict settings. Social Science \& Medicine, 146, 276284. doi:10.1016/j.socscimed.2015.10.011

Lee, J. A. B. (1996). The empowerment approach to social work practice. In F. Turner (Ed.), Social work treatment: Interlocking theoretical approaches (pp. 218-249). New York, NY: The Free Press.

Machel, G., UNICEF, \& United Nations (UN). (1996). Impact of armed conflict on children. New York, NY: Author. Retrieved from https://www.un.org/ga/ search/view_doc.asp?symbol=A/51/306

Madden, M., \& Ross, A. (2009). Genocide and GIScience: Integrating personal narratives and geographic information science to study human rights. The Professional Geographer, 61(4), 508-526. doi:10.1080/00330120903163480

Makhoul, J., \& Ghanem, M. (2009). Displaced Arab families: Mothers' voices on living and coping in postwar Beirut. Journal of Middle East Women's Studies, 5(3), 54-73. doi:10.2979/MEW.2009.5.3.54

Mancoske, R. J., \& Hunzeker, J. M. (1990). Empowerment based generalist practice: Direct services with individuals. New York, NY: Cummings and Hathaway.

Meertens, D., \& Stoller, R. (2001). Facing destruction, rebuilding life: Gender and the internally displaced in Colombia. Latin American Perspectives, 28(1), 132148. doi:10.1177/0094582X0102800108 
Midgley, J. (2014). Defining social development. In Social development: Theory and practice (pp. 3-19). London: SAGE Publications. doi:10.4135/9781446294 987.n1

Murray, L. K., Tol, W., Jordans, M., Sabir, G., Amin, A. M., Bolton, P., ... Thornicroft, G. (2014). Dissemination and implementation of evidence based, mental health interventions in post-conflict, low resource settings. Intervention, 12(Supplement 1), 94-112. doi:10.1097/WTF.0000000000000070

Nakimuli-Mpungu, E., Okello, J., Kinyanda, E., Alderman, S., Nakku, J., Alderman, S., ... Musisi, S. (2013). The impact of group counseling on depression, post-traumatic stress and function outcomes: A prospective comparison study in the Peter C. Alderman trauma clinics in northern Uganda. Journal of Affective Disorders, 151(1), 78-84. doi:10.1016/j.jad.2013.05.055

Ntakiyimana, F. (2005). Impact of armed conflicts on children, families and communities. Exchange: The Early Childhood Leaders' Magazine Since 1978, 163, 79-82.

Omona, J., \& Aduo, J. R. (2013). Gender issues during post-conflict recovery: The case of Nwoya District, northern Uganda. Journal of Gender Studies, 22(2), 119-136. doi:10.1177/002087287902200303

Puffer, E. S., Green, E. P., Chase, R. M., Sim, A. L., Zayzay, J., Friis, E., ... Boone, L. (2015). Parents make the difference: A randomized-controlled trial of a parenting intervention in Liberia. Global Mental Health, 2. doi:10.1017/ gmh.2015.12

Roberts, B., Odong, V. N., Browne, J., Ocaka, K. F., Geissler, W., \& Sondorp, E. (2009). An exploration of social determinants of health amongst internally displaced persons in northern Uganda. Conflict and Health, 3, 1-10. doi:10.1186/1752-1505-3-10

Uganda Bureau of Statistics (UBOS). (2018). Uganda national household survey, 2016-2017. Kampala, Uganda: Author. Retrieved from https://www.ubos. org/wp-content/uploads/publications/03_20182016_UNHS_FINAL_ REPORT.pdf

Uganda Bureau of Statistics (UBOS). (2020). Census 2014-Population by district. Kampala, Uganda: Bureau of Statistics. Retrieved from https://www.ubos. org/data-portals-2/visualizations/3/

Unruh, J. D. (2008). Toward sustainable livelihoods after war: Reconstituting rural land tenure systems. Natural Resources Forum, 32(2), 103-115. doi:10.1111/j.1477-8947.2008.00184.x

Whyte, S. R., Babiiha, S. M., Mukyala, R., \& Meinert, L. (2013). Remaining internally displaced: Missing links to security in Northern Uganda. Journal of Refugee Studies, 26(2), 283-301. doi:10.1093/jrs/fes040 